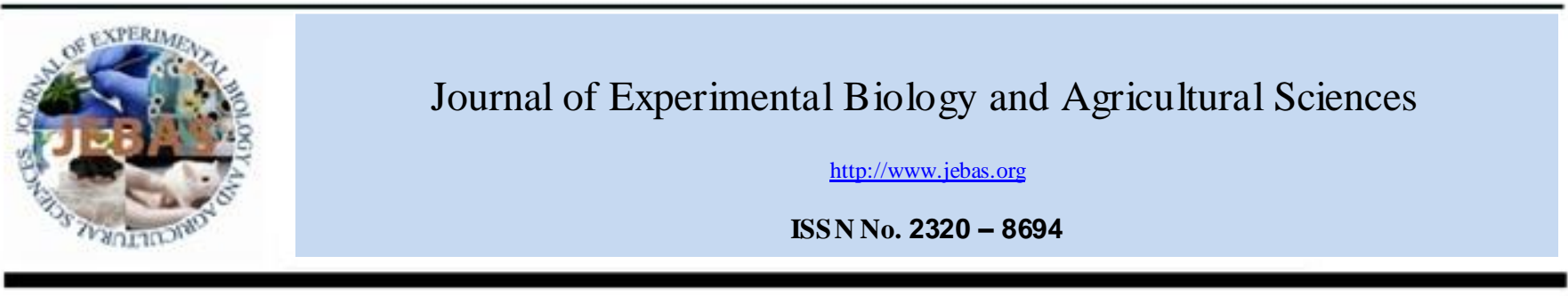

\title{
PATH ANALYSIS OF THE MAIN ECONOMIC CHARACTERS OF THE INNER MONGOLIA WHITE CASHMERE GOATS
}

\section{JunYan Bai ${ }^{1} *$, Xiao Ping $\mathrm{Jia}^{2}$, Yu Qin $\mathrm{Wang}^{1}$ and You Zhi Pang ${ }^{1}$}

${ }^{1}$ College of Animal Science and Technology, Henan University of Science and Technology, Henan, Luoyang 471003, China

${ }^{2}$ College of Agriculture, Henan University of Science and Technology,Henan, Luoyang 471003, China

Received - February 12, 2015; Revision - February 24, 2015; Accepted - June 08, 2015

Available Online - June 19, 2015

DOI: http://dx.doi.org/10.18006/2015.3(3).269.274

\section{KEYWORDS \\ Inner Mongolia White \\ Cashmere Goats \\ Cashmere Yield \\ Path Analysis \\ Regression Equation}

\begin{abstract}
ABSTRAC T
In this paper, the correlation coefficients among the various economic characters of the Inner Mongolia white cashmere goats such as cashmere yield $(\mathrm{Y})$, body weight $\left(\mathrm{X}_{1}\right)$, cashmere thickness $\left(\mathrm{X}_{2}\right)$, staple length $\left(\mathrm{X}_{3}\right)$, cashmere fineness $\left(\mathrm{X}_{4}\right)$ and cashmere stretched length $\left(\mathrm{X}_{5}\right)$ are analyzed with the SA S8.1 software, and the regression equation between the cashmere yield and other economic characters is established based on the path analysis. The results shows that the main factor determining the cashmere yield of rams is the body weight and that of ewes is the cashmere thickness of the cashmere, followed by the body weight. The regression equations of rams and ewes between the cashmere yield and other economic characters were $\mathrm{Y}=7.0462 \mathrm{X}_{1}+15.6568 \mathrm{X}_{2}-7.2930 \mathrm{X}_{3}+14.5744 \mathrm{X}_{5}$ and $\mathrm{Y}=-$ $176.8148+5.0321 \mathrm{X}_{1}+45.5121 \mathrm{X}_{2}-3.4524 \mathrm{X}_{3}+15.6498 \mathrm{X}_{4}+18.7189 \mathrm{X}_{5}$, respectively. It's recommended to put emphasis on the body weight and cashmere yield and give dual attention to the cashmere thickness and cashmere fineness when breeding the Inner Mongolia white cashmere goats, in order to obtain good breeding effect.
\end{abstract}

* Corresponding author

E-mail: junyanbai@163.com (JunYan Bai)

Peer review under responsibility of Journal of Experimental Biology and Agricultural Sciences.

Production and Hosting by Horizon Publisher (www.my-

vision.webs.com/horizon.html).

All rights reserved.
All the article published by Journal of Experimental Biology and Agricultural Sciences is licensed under a Creative Commons Attribution-NonCommercial 4.0 International License Based on a work at www.jebas.org.

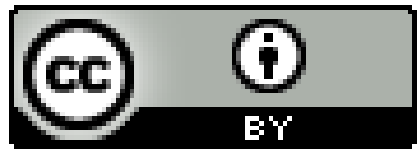




\section{Introduction}

Various kinds of cashmere goats are used for various purposes. Particularly, the cashmere (referring to the downy unmyelinated fiber grown from the secondary hair follicle in the under layer of the goat hair) has the special characteristics in the international market. Being extra fine, white, soft and bright, the fiber is a traditional rare and advanced textile material. The produced fabric is thin, light, warm, smooth, comfortable, beautiful and elegant at high prices, promoting the development of the international cashmere goat industry (Li et al.,2001). Not only the traditional cashmere goat breeding countries are actively involved in the cashmere goat breeding and research work, but also the animal husbandry developed countries like Australia, New Zealand, the UK and the US also successively develop and establish the cashmere goat bases and control the weeds and shrubs and improve the grassland through grazing the goats (Jia et al., 1994). At the same time, they vigorously carry out scientific research to improve the production level of the cashmere goats. With the favorable advantages of the cashmere goat resources, China has made great achievements in the cashmere goat breeding and accumulated rich information, but due to the poor basis and late start of the cashmere goat genetic breeding work, the existing research level is still low and there are a lot of work needing to be done (Jia et al., 1994; Jia et al., 1999).

Formed after the long-term breeding, the Inner Mongolia white cashmere goat is an improved local variety with the dual purpose of cashmere and meat. The Inner Mongolia white cashmere goats are found in the Inner Mongolia Autonomous Region. They are divided into three types, namely, Aerbasi cashmere goat, Erlang san cashmere goat and Alashan cashmere goat (Bai et al., 2006). In April 1988, they were accepted and named the Inner Mongolia white cashmere goat by the People's Government of the Autonomous Region. Since the introduction of the quantitative genetics in the 1920s, the animal breeding method has been developing rapidly, leading to the great achievements in the breeding work and the huge progress in the production level of animal and poultry (Jia et al.,1999). Some new theories and methods of animal genetics and breeding are widely applied in the breeding of cows, chickens, pigs, fine-wool sheep, beef cattle, mutton sheep, milk goats and hairy goats. However, due to the late start, the cashmere goat breeding lags behind other breeds in the breeding theory and method (Jia et al., 1999). In the cashmere goat research is currently mainly concentrated in the estimation of genetic parameters (Bai et al., 2004) and gene on production traits influence (Lan et al., 2012).

This paper conducts a regression analysis between the cashmere yield of the Inner Mongolia white cashmere goat and other economic characters and discusses the relationship among the economic characters, in order to provide some references for the scientific breeding and variety breeding of the Inner Mongolia white cashmere goats.

\section{Materials and methods}

The test data are from the record data of 759 rams and 3836 ewes in a cashmere goat farm in Inner Mongolia, including 6 economic characters viz cashmere yield, body weight, cashmere thickness, staple length, cashmere fineness and straight length. For the sake of convenience, these 6 indicators will be abbreviated to $\mathrm{Y}, \mathrm{X}_{1}, \mathrm{X}_{2}, \mathrm{X}_{3}, \mathrm{X}_{4}$ and $\mathrm{X}_{5}$, respectively.

Inner Mongolia white cashmere goat was provided by Inner Mongolia Yimeng Arbas white cashmere goat breeding farm, the sheep sheep herder groups according to a fixed feeding, year-round grazing in winter and spring, the quantitative feeding feed. Every spring, unified administration, immune sheep wash, insecticide, unified breeding in autumn, spring lambing. 4 to June each year between the unity of performance measurement in the same place, the cashmere yield and body weight were measured, including cashmere thickness, staple length, cashmere fineness and straight length sample parts are on the side of the body of scapula backward a cashmere goat cashmere, cashmere fineness and the stretched length is determined under the microscope. The correlation analysis and path analysis are conducted with MEANS, CORR and REG of SAS8.1 software.

\section{Results}

\subsection{Basic Statistics Analysis}

The basic statistics of the cashmere yield, body weight and hair characters of the Inner Mongolia white cashmere ram and ewe goats have been represented in Table 1. According to Table 1, the variation coefficient was reported highest for the body weight of rams this weight was followed by the cashmere yield, being $33.10 \%$ and $30.62 \%$, respectively. According to Table 2, the variation coefficient of the cashmere yield of ewes was the largest which followed by the body weight, being $28.54 \%$ and $22.63 \%$, respectively, indicating that the cashmere yield and body weight of this variety change greatly and there are great potential in the cashmere yield and body weight when selecting the Inner Mongolia white cashmere goats.

\subsection{Correlation Analysis}

The correlation coefficients among various economic characters of the Inner Mongolia white cashmere ram and ewe goats were shown in Table 2. It can be seen in Table 2 that the body weight, cashmere yield and hair character of rams are positively correlated with each other to varied extents $(\mathrm{P}<0.01)$, in which the coefficients correlated with the body weight were as follow cashmere fineness > cashmere yield > cashmere thickness $>$ staple length $>$ length; the coefficients correlated with the cashmere yield follow: body weight > cashmere fineness > length > cashmere thickness > staple length. 
Table 1.Basic statistics of economic traits in Inner Mongolia Cashmere Goats.

\begin{tabular}{|c|c|c|c|c|c|c|c|}
\hline Sex & Statistics & $\begin{array}{c}\text { Cashmer } \\
\text { e yield } \\
(\mathrm{g})\end{array}$ & $\begin{array}{c}\text { Body } \\
\text { weight } \\
(\mathrm{kg})\end{array}$ & $\begin{array}{c}\text { Cashmere } \\
\text { thickness } \\
(\mathrm{cm})\end{array}$ & $\begin{array}{c}\text { Staple } \\
\text { length } \\
(\mathrm{cm})\end{array}$ & $\begin{array}{c}\text { Cashmere } \\
\text { fineness } \\
(\mu \mathrm{m})\end{array}$ & $\begin{array}{c}\text { Cashmere } \\
\text { stretched } \\
\text { length }(\mathrm{cm})\end{array}$ \\
\hline \multirow[t]{7}{*}{ Ram } & The sample size & 759 & 759 & 759 & 759 & 759 & 759 \\
\hline & Mean & 533.39 & 34.64 & 5.87 & 19.73 & 13.01 & 9.92 \\
\hline & Min & 205.00 & 20.50 & 3.00 & 10.00 & 10.32 & 6.39 \\
\hline & $\operatorname{Max}$ & 1135.00 & 77.00 & 10.00 & 30.00 & 17.33 & 15.36 \\
\hline & Standard deviation & 163.34 & 11.46 & 1.12 & 2.98 & 1.11 & 1.63 \\
\hline & Standard error of the mean & 5.93 & 0.42 & 0.04 & 0.11 & 0.04 & 0.06 \\
\hline & Coefficient of variation $(\%)$ & 30.62 & 33.10 & 19.24 & 15.10 & 8.55 & 16.52 \\
\hline \multirow[t]{7}{*}{ Ewe } & The sample size & 3836 & 3836 & 3836 & 3836 & 3836 & 3836 \\
\hline & Mean & 547.38 & 27.71 & 5.66 & 16.96 & 13.77 & 9.07 \\
\hline & Min & 200.00 & 15.00 & 3.00 & 6.00 & 10.25 & 5.00 \\
\hline & Max & 1220.00 & 47.00 & 9.00 & 30.00 & 18.28 & 19.32 \\
\hline & Standard deviation & 156.19 & 6.26 & 0.87 & 3.52 & 1.06 & 1.35 \\
\hline & Standard error of the mean & 2.52 & 0.10 & 0.01 & 0.06 & 0.02 & 0.02 \\
\hline & Coefficient of variation $(\%)$ & 28.54 & 22.63 & 15.36 & 20.76 & 7.76 & 14.97 \\
\hline
\end{tabular}

For ewes, except that the length is negatively correlated with the body weight, length and cashmere fineness, other characters are positively correlated with each other, in which the coefficients correlated with the body weight were as follow: cashmere fineness > cashmere yield > cashmere thickness > length > staple length and the coefficients correlated with the cashmere yield follow: cashmere thickness $>$ body weight $>$ cashmere fineness $>$ length $>$ staple length.
Most characters are positively correlated with each other, indicating the inter-relationship between the body weight and cashmere yield of the white cashmere goats and the characters of the cashmere. The phenotypic correlation among them has a useful reference for the selection of the economic characters. Therefore, all characters should be taken into account when selecting the body weight and cashmere yield for the best results.

Table 2 Correlation between economic traits of Inner Mongolia Cashmere Goats.

\begin{tabular}{|c|c|c|c|c|c|c|c|}
\hline Sex & Traits & $\begin{array}{c}\text { Cashmere } \\
\text { yield } \\
(\mathrm{g})\end{array}$ & $\begin{array}{c}\text { Body } \\
\text { weight } \\
(\mathrm{kg})\end{array}$ & $\begin{array}{l}\text { Cashmere } \\
\text { thickness } \\
(\mathrm{cm})\end{array}$ & $\begin{array}{l}\text { Staple } \\
\text { length } \\
(\mathrm{cm})\end{array}$ & $\begin{array}{c}\text { Cashmere } \\
\text { fineness } \\
(\mu \mathrm{m})\end{array}$ & $\begin{array}{r}\text { Cashmere } \\
\text { stretched } \\
\text { length }(\mathrm{cm}\end{array}$ \\
\hline \multirow[t]{6}{*}{ Ram } & Cashmere yield(g) & 1.0000 & & & & & \\
\hline & Body weight $(\mathrm{kg})$ & $0.6104^{* *}$ & 1. 000 & & & & \\
\hline & Cashmere thickness $(\mathrm{cm})$ & $0.4345^{* *}$ & $0.5690^{* *}$ & 1.0000 & & & \\
\hline & Staple length $(\mathrm{cm})$ & $0.2635^{* *}$ & $0.5013^{* *}$ & $0.5759^{* *}$ & 1.0000 & & \\
\hline & Cashmere fineness $(\mu \mathrm{m})$ & $0.4542^{* *}$ & $0.6755^{* *}$ & $0.5317^{* *}$ & $0.4621^{* * *}$ & 1.0000 & \\
\hline & Cashmere stretched length $(\mathrm{cm})$ & $0.4367^{* *}$ & $0.5077^{* *}$ & $0.5792^{* *}$ & $0.3716^{* *}$ & $0.3769^{* *}$ & 1.0000 \\
\hline \multirow[t]{6}{*}{ Ewe } & Cashmere yield(g) & 1.0000 & & & & & \\
\hline & Body weight $(\mathrm{kg})$ & $0.2739^{* *}$ & 1.0000 & & & & \\
\hline & Cashmere thickness $(\mathrm{cm})$ & $0.3535^{* *}$ & $0.1741^{* *}$ & 1.0000 & & & \\
\hline & Staple length $(\mathrm{cm})$ & $0.0684^{* *}$ & $0.1370^{* *}$ & $0.3250^{* *}$ & 1.0000 & & \\
\hline & Cashmere fineness $(\mu \mathrm{m})$ & $0.2475^{* *}$ & $0.5074^{* *}$ & $0.2233^{* *}$ & $0.1369^{* *}$ & 1.0000 & \\
\hline & Cashmere stretched length $(\mathrm{cm})$ & $0.2305^{* *}$ & $-0.0978^{* *}$ & $0.4064^{* *}$ & $0.1325^{* *}$ & $-0.0492^{* *}$ & 1.0000 \\
\hline
\end{tabular}

Notes: **: that the correlation coefficient between the two traits is very significant $(\mathrm{P}<0.01)$, *: indicates the correlation coefficient between the two traits as a significant $(\mathrm{P}<0.05)$, other: that the correlation coefficient bet ween the two traits was not significant $(\mathrm{P}>0.05)$. 


\subsection{Path analysis}

According to the principle of the path analysis, the phenotypic correlation among the characters of rams and eves can be used to establish the path coefficient equation set 1 and 2 on the cashmere yield.

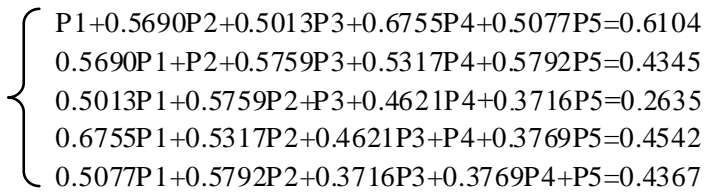

Solve the equation set 1 to get: $\mathrm{P} 1=0.4947, \mathrm{P} 2=0.1083, \mathrm{P} 3=$ $0.1330, \mathrm{P} 4=0.0687$ and $\mathrm{P} 5=0.1463$, in which $\mathrm{P} 1, \mathrm{P} 2, \mathrm{P} 3, \mathrm{P} 4$ and $\mathrm{P} 5$ represent the path coefficients of the body weight, cashmere thickness and staple length of the rams and the cashmere thickness and cashmere fineness of the cashmere on the cashmere yield. Thus, the body weight of the ram has the biggest direct influence on the cashmere yield. It's followed by the straight length, staple length, cashmere thickness and cashmere fineness, in which the staple length has the negative influence on the cashmere yield.

Solve the equation set 1 to get: $\mathrm{P} 1=0.2020, \mathrm{P} 2=0.2536, \mathrm{P} 3=$ $0.0779, \mathrm{P} 4=0.1070$ and $\mathrm{P} 5=0.1628$. Thus, the cashmere thickness of ewes has the biggest direct influence on the cashmere yield. It's followed by the body weight, straight length, cashmere fineness and staple length, in which the staple length has the negative influence on the cashmere yield. $\int \mathrm{P} 1+0.1741 \mathrm{P} 2+0.1370 \mathrm{P} 3+0.5074 \mathrm{P} 4-0.0978 \mathrm{P} 5=0.2739$

$0.1741 \mathrm{P} 1+\mathrm{P} 2+0.3250 \mathrm{P} 3+0.2233 \mathrm{P} 4+0.4064 \mathrm{P} 5=0.3535$

$\left\{\begin{array}{l}0.1370 \mathrm{P} 1+0.3250 \mathrm{P} 2+\mathrm{P} 3+0.1369 \mathrm{P} 4+0.1325 \mathrm{P} 5=0.0684 \\ 0.5074 \mathrm{P} 1+0.2233 \mathrm{P} 2+0.36 \mathrm{P} 3+\mathrm{P} 40.04925=0.245\end{array}\right.$

$0.5074 \mathrm{P} 1+0.2233 \mathrm{P} 2+0.1369 \mathrm{P} 3+\mathrm{P} 4-0.0492 \mathrm{P} 5=0.2475$

$-0.0978 \mathrm{P} 1+0.4064 \mathrm{P} 2+0.1325 \mathrm{P} 3-0.0492 \mathrm{P} 4+\mathrm{P} 5=0.2305$

\subsection{Correlation Coefficient Subdivision}

The subdivision results of the influence of the economic characters of the inner Mongolia white cashmere goats on the cashmere yield were shown in Table 3. According to Table 3, for rams, the staple length has the biggest indirect influence on the cashmere yield with the coefficient of 0.3965 and its direct influence was negative. The indirect influence of other characters through the staple length is negative, either; the coefficients of the indirect influence were 0.3854 for cashmere fineness and 0.3261 for cashmere thickness.

The direct influence of the body weight on the cashmere yield was 0.4947 and the smallest indirect influence is 0.1156 . The indirect influence of all characters on the cashmere yield through the body weight was big, varying between 0.2480 and 0.3342 . All these show that the influence of the staple length, cashmere fineness, cashmere thickness and cashmere stretched length of rams on the cashmere yield depends on the indirect effect; the body weight not only has a strong direct influence on the cashmere yield, but also assists other characters to exert great indirect effect on it.

Table 3 Impact on the cashmere yield.

\begin{tabular}{|c|c|c|c|c|c|c|c|c|c|}
\hline \multirow[t]{2}{*}{ Sex } & \multirow[t]{2}{*}{ Traits } & \multirow{2}{*}{$\begin{array}{l}\text { Correlation } \\
\text { coefficient }\end{array}$} & \multirow{2}{*}{$\begin{array}{l}\text { Direct } \\
\text { effects }\end{array}$} & \multicolumn{6}{|c|}{ Indirect effects } \\
\hline & & & & $\begin{array}{c}\text { Body } \\
\text { weight } \\
(\mathrm{kg})\end{array}$ & $\begin{array}{l}\text { Cashmere } \\
\text { thickness } \\
(\mathrm{cm})\end{array}$ & $\begin{array}{l}\text { Staple } \\
\text { length } \\
(\mathrm{cm})\end{array}$ & $\begin{array}{c}\text { Cashmere } \\
\text { fineness } \\
(\mu \mathrm{m})\end{array}$ & $\begin{array}{l}\text { Cashmere } \\
\text { stretched } \\
\text { length }(\mathrm{cm})\end{array}$ & Sum \\
\hline \multirow[t]{5}{*}{ Ram } & Body weight $(\mathrm{kg})$ & 0.6104 & 0.4947 & & 0.0616 & -0.0667 & 0.0464 & 0.0743 & 0.1156 \\
\hline & Cashmere & 0.4345 & 0.1083 & 0.2815 & & -0.0766 & 0.0365 & 0.0847 & 0.3261 \\
\hline & Staple length $(\mathrm{cm})$ & 0.2635 & -0.1330 & 0.2480 & 0.0624 & & 0.0317 & 0.0544 & 0.3965 \\
\hline & Cashmere & 0.4542 & 0.0687 & 0.3342 & 0.0576 & -0.0615 & & 0.0551 & 0.3854 \\
\hline & $\begin{array}{l}\text { Cashmere } \\
\text { stretched }\end{array}$ & 0.4367 & 0.1463 & 0.2516 & 0.0627 & -0.0494 & 0.0259 & & 0.2908 \\
\hline \multirow[t]{5}{*}{ Ewe } & Body weight(kg) & 0.2739 & 0.2020 & & 0.0442 & -0.0107 & 0.0543 & -0.0159 & 0.0719 \\
\hline & Cashmere & 0.3535 & 0.2536 & 0.0352 & & -0.0253 & 0.0239 & 0.0662 & 0.0999 \\
\hline & Staple length $(\mathrm{cm})$ & 0.0684 & -0.0779 & 0.0277 & 0.0824 & & 0.0146 & 0.0216 & 0.1463 \\
\hline & Cashmere & 0.2475 & 0.1070 & 0.1025 & 0.0566 & -0.0107 & & -0.0080 & 0.1404 \\
\hline & $\begin{array}{l}\text { Cashmere } \\
\text { stretched }\end{array}$ & 0.2305 & 0.1628 & -0.0198 & 0.1031 & -0.0103 & -0.0053 & & 0.0677 \\
\hline
\end{tabular}


For ewes, the staple length has the largest indirect influence of 0.1463 on the cashmere yield, but its indirect influence was negative. The influence was exerted through the cashmere thickness. The indirect influence of other characters through the staple length was negative, either; the indirect influence of the cashmere fineness was 0.1404 and that of the cashmere thickness was 0.0999. The cashmere stretched length has the smallest indirect influence on the cashmere yield of 0.0667 . It mainly exerts the influence through the cashmere thickness and its influence through other characters was negative. The indirect influence of the characters on the cashmere thickness through the body weight was very high and it varied from 0.0442 to 0.1031 . Thus, the influence of the staple length and cashmere fineness of ewes on the cashmere yield mainly depends on the indirect effect; the body weight and cashmere fineness have the strong direct influence on the cashmere yield; the cashmere thickness not only has strong direct influence on the cashmere yield, but also assists other characters to exert great direct influence on it.

\subsection{Optimal regression equation is established}

It's found through the significance test on the intercept and 5 regression coefficients of the cashmere yield regression model that the regression coefficients of the intercept and cashmere fineness do not reach the significant level and those of other characters reach the extremely significant level. After eliminating the characters with the not significant coefficients, the regression equation is: $\mathrm{Y}=7.0462 \mathrm{X}_{1}+15.6568 \mathrm{X}_{2}$ $7.2930 X_{3}+14.5744 X_{5}$. Similarly, the regression equation of the cashmere yield of ewes was $\mathrm{y}=$ $176.8148+5.0321 \mathrm{X}_{1}+45.5121 \mathrm{X}_{2}-$ $3.4524 \mathrm{X}_{3}+15.6498 \mathrm{X}_{4}+18.7189 \mathrm{X}_{5}$.

\section{Discussions}

The research of Xiaohong et al. (2004) shows that the body length $\left(\mathrm{X}_{2}\right)$, chest circumference $\left(\mathrm{X}_{3}\right)$, shin circumference $\left(\mathrm{X}_{4}\right)$, staple length $\left(\mathrm{X}_{6}\right)$ and body weight $\left(\mathrm{Y}_{1}\right)$ of Liaoning white cashmere goats have the significant positive correlation with each other $(\mathrm{P}<0.01)$. The optimal regression equation is established as: $\quad \mathrm{Y}_{1}=-46.306+0.327 \mathrm{X}_{2}+0.587 \mathrm{X}_{3}+$ $0.780 \mathrm{X}_{4}+0.288 \mathrm{X}_{6}$. According to the equation, the body weight of the cashmere goats has the reliability of more than $95 \%$. They think the chest circumference of Liaoning white cashmere goats has the biggest influence on the body weight and the body length, shine circumference and staple length indirectly affect the body weight through the chest circumference; the staple length has the biggest influence on the cashmere yield, but the optimal regression equation cannot be found through the body height and length, chest circumference, shine circumference, staple length and cashmere yield. Tong-jun et al. (2003) argue that the body size of Jianchang black goats at all ages has different degrees of correlation with the body weight. The chest circumference plays the decisive role on the body weight when the goat is at 2 years old. It's followed by the interactive effect between the chest circumference and the back height. It's the key time for the breeding selection and mating combination. The optimal regression model of the body size of the replacement and adult Hainan black goats on the body weight established by Xu et al. (2005) recommends to give due consideration to the chest circumference selection besides the body weight when selecting the high grow rate line of Hainan black goats. Han et al. (2006) analyzes the correlation between the body size and the body weight of Duhan F1 lambs at 6 months old and establishes the regression equitation of the body size on the body body weight. He thinks that there is a significant correlation with the body size indicators and the body weight of Duhan F1 lambs $(\mathrm{P}<0.05)$; and, the body length and chest depth mainly exert the direct influence and others exert the indirect influence. The decisive coefficient analysis shows that the chest depth and body length of Duhan F1 have a greater influence on the body weight.

At preset some scholars of the cashmere goat body measurements and cashmere yield of correlation and regression analysis, for example, Zeng et al. (2014) study showed the effect of body weight, body height of Shanbei white cashmere goat cashmere yield was significant, regression equation is $\mathrm{Y}=-574.771+18.067 \mathrm{X} 1+19.542 \mathrm{X} 2$ can well reflect the linear the relationship between the indicators. Yiming et al. (2014) results showed that: the cashmere goat green Gerry weight (X1), body height (X2), body length (X3), chest circumference (X4), (X5), the fiber length (X6) and cashmere yield (Y) showed a significant positive correlation $(\mathrm{P}<0.01)$. The direct effect of body weight and chest circumference of cashmere yield and body height is large, mainly through the indirect effect of cashmere yield. The optimal regression equation: $\mathrm{Y}=$ $0.267 \times 10.094 \times 30.231 \times 40.047 \times 50.089 \times 6 . \mathrm{Li}$ et al. (2014) studies show that the farming pastoral zone feeding the measurement indexes of Liaoning cashmere goat body height, body length, chest girth, chest width, chest depth and body are important factors affecting body weight.

The results of this research are slightly different from the findings of Li et al. (2014). After the significance test on the multiple optimal regression model of the cashmere yield of the Inner Mongolia white cashmere ram and ewe goats, the regression correlations are extremely significant $(\mathrm{P}<0.01)$, indicating the real multiple regression relationship between the cashmere yield and the hair characters of the Inner Mongolia white cashmere goats. This equation is of certain reference value.

It can be seen from the correlation analysis, path analysis and decisive degree analysis that the body weight determines the cashmere yield of rams. Therefore, the focus should be put on the cashmere yield with the due consideration to the body weight when selecting the Inner Mongolia white cashmere ram goats for breeding, in order to obtain good breeding effect. The cashmere thickness determines the cashmere yield of ewes, followed by the body weight. Therefore, the focus should be 
put on the cashmere yield with the due consideration to the cashmere thickness and body weight when selecting the Inner Mongolia white cashmere ram goats for breeding, in order to obtain good breeding effect.

\section{Conflict of interest}

Authors would hereby like to declare that there is no conflict of interests that could possibly arise.

\section{References}

Li JQ,Yin J (2001) Cashmere goats breeding research status and prospects.Grass-feeding Livestock(China) 1: 19-23.

Jia ZH (1994) Foreign research status and prospects of cashmere goats.Chinese Journal of Animal Science 30:57-59.

Jia ZH, Peng YL, Fu JC (1999) Current situation and prospects of chinese cashmere goat breeding. Chinese Jo urnal of Animal Science 35:55-57.

Bai JY, Jia XH, Li JQ, Dao EJ (2006) Chinese cashmere goat breeding research progress.Inner Mongolia Agricultural Science And Technology 2: 20-22.

Bai JY, Li JQ, Dao EJ, Zhang Q (2004) Comparison of Different Models for Estimating Genetic Parameters of Early Growth Traits in Cashmere Goat. Acta Genetica Sinica 31: 578-581.

Lan X, Zhao H, Wu CY, Hu S, Pan C, Lei C, Chen H (2012) Analysis of genetic variability at codon 42 within caprine prion protein gene in relation to production traits in Chinese domestic breeds. Molecular Biology Reports 39:4981-4988.
Xiaohong HE, Tao Z, Yani Z, Shemin G (2004) Multiple statistical analysis of the effect of body measurerment,wool trait and economic trait on cashmere goat. Journal of Northwest scitech university of Agriculture and Forestry (China) 32:85-92.

Tong-jun W (2003) A Research on Correlation Between Body Size and Body Weight of Jianchang Black Goat. Sichuan Animal \& Veterinary Sciences(China) 30:22-26.

Xu TS, Tong-jun JD, Liu XL, Hou GY, Xia WL, Hang XZ (2005) A research on path analysis and optimum regression equation between body size and body weight of hainan black goat. Acta Ecologiae Animalis Domastici(China) 26:49-53.

Han WJ, Chen YL, Feng T, An JJ (2006) Path analysis and optimum regr ession equation between body size and body weight of $\mathrm{F} 1(\mathrm{D} \times \mathrm{H})$ lamb. Hubei Agricultural Sciences (China) 45:57-59.

Zeng XF, Ma WE, Wen XX, Ta YY(2014) On the multivariate statistical model of body sizes and production performance about shanbei white cashmere goats. Journal of Yulin University (China) 24:31-35.

Yiming S, Li YF, Bahetibieke, Huang XX(2014) Correlation analysis on bdy size, body weight and cashmere yield of qinggeli cashmere goat. Journal of Xinjiang Agricultural University (China) 37:44-47.

Li JY, Chen Y, Jiang HZ(2014) Correlation analysis between body weight and body size of liaoning cashmere goat in horqin pastoral transitional zone. Modern Journal of Animal Husbandry and Veterinary Medicine (China) 12:18-21. 